\title{
O SENTIDO DE UMA OBRA \\ Sobre Sylvia Leser de Mello
}

\author{
Maria Helena Souza Patto ${ }^{1}$ \\ Instituto de Psicologia - USP
}

Vão me lembro bem da primeira vez que a vi. Na parede da memória resta
uma imagem vaga, mas suficiente para mostrá-la caminhando entre o Bloco 10 e o Bloco 1, em companhia de Lúcia Prado. Era um fim de tarde na Cidade Universitária, no começo dos anos setenta.

Mas lembro-me perfeitamente da primeira vez que a li. Formação profissional dos psicólogos: apontamentos para um estudo, artigo publicado em 1975, é síntese de sua tese de doutorado, defendida em 1972 e marco zero do trabalho da vida inteira de Sylvia Leser de Mello: trata-se de um escrito simples (porque direto), profundo (porque fundado em sólida formação teórica) e engajado politicamente (porque atento ao lugar da Psicologia como ciência e profissão no interior das relações sociais de poder). Na verdade, forma e conteúdo se irmanam nos escritos de Sylvia para dar-lhes o sentido político primordial: lá já estava a escrita certeira; lá já estavam citações inéditas na Psicologia nacional de filósofos e sociólogos críticos; lá já estava o compromisso que moverá uma longa obra de essência ético-política.

$\mathrm{Na}$ linguagem precisa, sem excessos ou pieguice, ela soma com $\mathrm{Ca}-$ mus de A Peste, de onde retirará, mais tarde, uma passagem que será epígrafe de seu livro Trabalho e Sobrevivência:

Digo apenas que há nesta cidade flagelo e vítimas

E é necessário não transigirmos com o flagelo. ...

Ouvi argumentos numerosos que me viraram quase a cabeça

1 Docente do Departamento de Psicologia da Aprendizagem, do Desenvolvimento e da Personalidade do Instituto de Psicologia-USP e atual diretora do Instituto de Psicologia da Universidade de São Paulo. Endereço eletrônico: mhspatto@usp.br 
e foram suficientes para levar outras cabeças a consentir no homicídio, e percebi que a desgraça dos homens vinha de não usarem linguagem clara. Decidi então falar e proceder claro, entrar no bom caminho. Digo, pois, que há flagelo e vítimas, nada mais.

Posso dizer, sem medo de errar, que os trabalhos e os dias de Sylvia nesses exatos cinqüenta anos dela na Universidade de São Paulo, desde o seu ingresso no curso de Filosofia, em 1956, têm sido uma árdua batalha travada no território das detestáveis relações de poder que atravessam como faca o corpo da história brasileira.

Não fui sua aluna, mas este texto de 1975 teve em mim uma influência fundadora, pois traduziu em palavras sensações que incomodavam a jovem docente recém-admitida no Instituto de Psicologia da Universidade de São Paulo. Em menos de cinco páginas, a autora fazia a mágica de assinalar as questões fundamentais desta ciência que surgira na segunda metade do século XIX com objetivos claramente adaptativos. Lá estava a questão da deficiência do ensino primário, secundário e superior. Lá estava o mal-estar dos estudantes universitários diante da distância entre o que se ensinava no curso de Psicologia e o que acontecia no país em tempos pesados de ditadura militar. Lá estavam as salas de aula esvaziadas, por motivos muito diversos dos que hoje despovoam as Unidades da USP. Lá estava o fracionamento do conhecimento transmitido, a descostura das várias concepções teóricas do comportamento humano. No centro do escrito, uma pergunta: o que é um psicólogo? Não um psicólogo abstrato, fora do tempo e do espaço, mas um psicólogo em situação: no caso, a realidade social brasileira.

Numa época de trabalho escasso para psicólogos (exceção feita aos consultórios particulares), ela imagina um cenário de expansão de demanda e pergunta preocupada: e se os psicólogos fossem chamados a trabalhar "com escolares, em escolas públicas de periferia, com as famílias desses escolares, com os professores e diretores dessas escolas, com menores órfãos e abandonados, nos recolhimentos de menores, nos orfanatos, com as pessoas que cuidam desses menores, com delinqüentes nas prisões, com os policiais e os juízes, com migrantes e suas famílias, chegados há pouco em São Paulo?" 
Para respondê-la, ela advertia, é preciso atentar para uma cilada contida no conceito de normalidade. Ao aderir acriticamente a ele, o psicólogo se põe a serviço da adaptação pela repressão, que rotula como anormais os que cometem o delito do uso da imaginação, da escolha de soluções pessoais, da recusa da obediência e da produtividade cegas que encontram sua mais perfeita realização nos burocratas de classe média, de terno e gravata no corpo e na alma, encarregados de polir arestas, amenizar conflitos, produzir a adesão ao estabelecido para garantir a vigência do autoritarismo contido no lema Ordem e Progresso. Um conceito de normalidade, enfim, que tem no cerne uma intimação que remete a uma passagem de Kafka em Na Colônia Penal, um de seus escritores preferidos:

Nossa sentença não soa severa.

O mandamento que o condenado infringiu

é escrito no seu corpo com o rastelo.

No corpo deste condenado, por exemplo

- o oficial apontou para o homem -

será gravado: Honra o teu superior!

A consideração crítica dos andaimes da Psicologia oficial punha no centro o problema do currículo, que não podia ser um conglomerado de cientificismo e profissionalização, mas devia incluir um conjunto de saberes que formasse psicólogos cientes das desigualdades de classes e das especificidades das vidas numa sociedade dividida, comprometidos com a transformação e a humanização da vida social, com a emancipação coletiva e individual - em suma, movidos por um sentimento de justiça. Este tornou-se o coração da docência, da pesquisa e da extensão universitária praticadas por Sylvia.

Não nos esqueçamos da data desta publicação grávida de indignação e resistência: a primeira metade dos anos setenta. Foi a partir de então que criei um bordão que passou a fazer parte, como brincadeira séria, de minha relação com esta colega que formulou as questões que passaram a ocupar e ocupam até hoje professores e alunos no Instituto de Psicologia: "quando eu crescer, quero ser como você". Tenho certeza de que não fui a única. 
Se tomo esse texto como ponto de partida desta fala é por causa da riqueza contida em sua linhas e entrelinhas que o torna um novelo de temas - educação, relações familiares, aparato jurídico-policial, trabalho, migração - de onde será puxado o fio condutor de uma obra seminal e muito peculiar. É que o Instituto de Psicologia teve a felicidade de contratar uma intelectual formada em Filosofia, quem sabe num momento de descuido - num providencial momento de descuido -, quem sabe num momento de lucidez. Foi Carolina Bori quem providenciou a vinda de Sylvia do Departamento de Pedagogia da FFCL para o Instituto de Psicologia e orientou a sua tese de doutorado, cujo tema inicial - Família e Autoridade, na melhor tradição frankfurtiana - foi impossibilitado pela Ditadura Militar, já que os sujeitos eram pais do tão agredido Colégio de Aplicação. Foi assim que, em 1972, ela defendeu a tese As atividades profissionais e o psicólogo em São Paulo.

De um lado, a face militante de sua produção, que baniu os mitos da neutralidade e da objetividade científicas porque sabe que considerar idênticos o objeto e o método das Ciências Naturais e das Ciências Humanas é procedimento a serviço da dominação, pois reifica uma realidade social infestada pela peste da exploração econômica e da opressão política. Trabalho e Sobrevivência, obra-prima publicada em 1988, é exemplo disso: não fosse a transformação nela contida dos tradicionais “objetos da pesquisa" em sujeitos na produção de saber, seria impossível conhecer a substância da vida de mulheres do campo e da periferia de São Paulo, conhecimento esse inacessível a um discurso sobre elas e só possível a ouvidos atentos ao discurso delas.

Dona Maria, Maria José, Maria Ramos da Silva, Loura, Emília, Verônica, Odília, Nilza - as mulheres ouvidas por Sylvia, ou melhor, com quem Sylvia conversou longamente nos longos dias passados com elas em suas casas - ensinaram a todos nós que onde há faina, lida, labuta, a vida e o trabalho são uma coisa só. Solicitadas a falar do trabalho, elas contaram a vida; solicitadas a contar a vida, contaram uma história de trabalho. O tempo todo da pesquisa, Hannah Arendt foi parceira com quem Sylvia pensou teoricamente o conteúdo e a forma desse seu encontro poderoso com mulheres do campo e da periferia de São Paulo.

O artigo Classes populares, família e preconceito (1992) é outro exemplo de linguagem direta, solidez teórica e claro compromisso político com os 
oprimidos, agora a serviço da desconstrução do mito da família dos pobres como "família desorganizada", de trágicas consequiências para a vida de seus membros, não só porque justifica o seqüestro de suas crianças para transformálas em filhos de um Estado-padrasto, mas também porque é poderoso e sutil instrumento político de culpabilização dos pobres por suas péssimas condições de vida, na verdade geradas no ventre de uma sociedade cuja classe dominante cuida, há mais de cinco séculos, para que não sejam paridos cidadãos.

Tendo como modelo a família nuclear monogâmica, idealizada, a-histórica, tida como verdadeira morada da felicidade, encontramos, na literatura psicológica, educacional e sociológica a crença de que os pobres padecem de uma desorganização familiar acentuada, responsabilizada pela baixa escolarização e pela violência de suas crianças e jovens. Sylvia vem para advertir:

Quanto mais afastados estamos dos estratos médios da população urbana, tanto mais as categorias de organização e desorganização, no que se refere à família, precisam ser abandonadas na avaliação dos modos de vida da população. Sabemos que as famílias da periferia e das favelas e cortiços divergem daquele modelo ideal de família. Não é razoável falar-se de desorganização, com o sentido claramente estigmatizante que a palavra adquiriu na literatura educacional e psicológica, quando estamos, de fato, diante de formas diferentes de organização. Quando o pesquisador se liberta do modelo, liberta-se, portanto, do preconceito e pode ver as famílias como elas são e não como deveriam ser.

O interesse pelas relações familiares e de gênero resultou na criação do Laboratório de Estudos da Família, Relações de Gênero e Sexualidade. Mas esse tema já lhe estava posto há muito: não por acaso, Jules e Jim, um clássico de François Truffaut, datado de 1961 - um belo filme sobre a condição da mulher, o casamento e a amizade - encantou a inteligência sensível da jovem recém-formada em Filosofia.

A coroar este veio militante, o trabalho mais recente de Sylvia na Incubadora Tecnológica de Cooperativas Populares da Universidade de São Paulo. Mesmo ciente de que, com a economia solidária, "a era da exploração não vai durar menos" (Brecht), ela sabe também que, para os trabalhadores envolvidos, não há outra saída. Para falar dele ninguém melhor do que o Prof. Paul Singer, num texto escrito especialmente para esta ocasião - Sylvia Leser de Mello e a Economia Solidária - e reproduzido neste dossiê. 
Como se pode ver, os rumos que Sylvia imprimiu à sua carreira universitária foram resposta fecunda à questão de fundo de sua tese de doutorado: o que é um psicólogo?

Volto ao começo. Estamos diante de uma psicóloga social sui generis, porque direta, bem fundamentada e com claro compromisso com a justiça social. Mas não só por isso; na verdade, ela sempre soube que sem o convívio com as demais Ciências Humanas e as Humanidades - a Filosofia, a Literatura e a Arte - a Psicologia fica reduzida a entendimento precário da complexidade humana. Sylvia insiste na importância da História para a Psicologia. Freqüentam suas noites de leituras desde Heródoto até os historiadores das mentalidades, passando pela história marxista inglesa dos trabalhadores sob o modo capitalista de produção. Sobre este aspecto de seus escritos, destaco o ensaio Psicologia e História: um diálogo possível, a ser publicado em breve.

Mas a Literatura talvez seja a paixão da vida inteira, só superada pela dedicação a Celso Beisigel e pelas duas filhas do casal: Mariana e Beatriz. Ou seja, Sylvia sempre soube que, sem dialogar com as Ciências Humanas e sem valer-se da Filosofia e da Literatura, a Psicologia está condenada a um organicismo empobrecedor, mas nada inóquo, pois é pela porta da naturalização do homem que entra a reificação dele. Como Roland Barthes, ela pensa que "a ciência é grosseira, a vida é sutil, e é para corrigir esta distância que a literatura nos importa." (Aula). Com Merleau-Ponty aprendeu que "a ciência manipula as coisas e renuncia a habitá-las." ( $O$ olho e o espirito). Sylvia habita as coisas da Psicologia.

São muitos os seus discípulos, entre os quais me incluo. São muitos os orientandos que, para além da mera repetição, dão continuidade à sua obra, tomando-a como ponto de partida na produção de saber. Por isso termino com um poema de Brecht. Não o belo Perguntas de um trabalhador que lê, que ouvi pela primeira vez na voz de Sylvia, mas um poema chamado De Todas as Obras: 
De todas as obras humanas, as que mais amo

São as que foram usadas.

Os recipientes de cobre com as bordas achatadas e com mossas,

Os garfos e facas cujos cabos de madeira

Foram gastos por muitas mãos: tais formas

São para mim as mais nobres. Assim também as lajes

Em volta das velhas casas, pisadas e

Polidas por muito pés, e entre as quais

Crescem tufos de grama: estas são obras felizes.

Admitidas no hábito de muitos

Com freqüencia mudadas, aperfeiçoam seu formato e tornam-se valiosas

Porque delas tantos se valeram.

Mesmo as esculturas quebradas

Com suas mãos decepadas, me são queridas. Também elas

São vivas para mim. Deixaram-nas cair, mas foram carregadas.

Embora acidentadas, jamais estiveram altas demais.

É assim a obra dela: ao alcance de todos, ela está nas salas de aulas; em dissertações e teses; nas práticas de profissionais que atuam na saúde, na educação, no aparato jurídico-policial e nas instituições que acolhem trabalhadores maltratados; nos melhores ensaios de Psicologia Social e do Trabalho e, mais importante que tudo, na própria vida dos humilhados e ofendidos eternamente em busca de direitos que lhes são negados ou doados como favor.

Valendo-me de um verso de Drummond, faço saber, a quem possa interessar, que os instrumentos de trabalho de Sylvia Leser de Mello são apenas duas mãos e o sentimento do mundo.

Recebido em: 29/11/2006

Aceito em: 05/12/2006 